\title{
The interdependence of continental warm cloud properties derived from unexploited solar background signals in ground-based lidar measurements
}

\author{
J. C. Chiu ${ }^{1}$, J. A. Holmes ${ }^{2}$, R. J. Hogan ${ }^{1}$, and E. J. O'Connor ${ }^{1,3}$ \\ ${ }^{1}$ Department of Meteorology, University of Reading, Reading, UK \\ ${ }^{2}$ Department of Physical Sciences, Open University, Milton Keynes, UK \\ ${ }^{3}$ Finnish Meteorological Institute, Helsinki, Finland \\ Correspondence to: J. C. Chiu (c.j.chiu@reading.ac.uk) \\ Received: 9 January 2014 - Published in Atmos. Chem. Phys. Discuss.: 3 April 2014 \\ Revised: 26 June 2014 - Accepted: 10 July 2014 - Published: 21 August 2014
}

\begin{abstract}
We have extensively analysed the interdependence between cloud optical depth, droplet effective radius, liquid water path (LWP) and geometric thickness for stratiform warm clouds using ground-based observations. In particular, this analysis uses cloud optical depths retrieved from untapped solar background signals that are previously unwanted and need to be removed in most lidar applications. Combining these new optical depth retrievals with radar and microwave observations at the Atmospheric Radiation Measurement (ARM) Climate Research Facility in Oklahoma during 2005-2007, we have found that LWP and geometric thickness increase and follow a power-law relationship with cloud optical depth regardless of the presence of drizzle; LWP and geometric thickness in drizzling clouds can be generally $20-40 \%$ and at least $10 \%$ higher than those in non-drizzling clouds, respectively. In contrast, droplet effective radius shows a negative correlation with optical depth in drizzling clouds and a positive correlation in non-drizzling clouds, where, for large optical depths, it asymptotes to $10 \mu \mathrm{m}$. This asymptotic behaviour in non-drizzling clouds is found in both the droplet effective radius and optical depth, making it possible to use simple thresholds of optical depth, droplet size, or a combination of these two variables for drizzle delineation. This paper demonstrates a new way to enhance ground-based cloud observations and drizzle delineations using existing lidar networks.
\end{abstract}

\section{Introduction}

The response of global mean surface temperature to emissions of greenhouse gases from human activities remains highly uncertain (e.g. Hawkins and Sutton, 2009). One of the primary sources of the uncertainty is how lowtopped boundary-layer clouds will respond to the temperature perturbation and subsequently amplify or dampen climate change (e.g. Bony and Dufresne, 2005; Bony et al., 2006). To improve representations of cloud properties and their interactions with radiation and water budget in models, sustained efforts have been made to observe and study marine low-topped clouds (e.g. Martin et al., 1994; Kubar et al., 2009; Bretherton et al., 2010; Wood, 2012). However, similar efforts have not been made for mid-latitude continental stratus and stratocumulus clouds, despite their strong links to local weather and climate (Del Genio and Wolf, 2000; Kollias et al., 2007), and their high occurrences compared to other cloud types over land (Sassen and Wang, 2008).

Ground-based observations for mid-latitude continental clouds are primarily provided by the Atmospheric Radiation Measurement (ARM) Climate Research Facility (Stokes and Schwartz, 1994), the NASA Aerosol Robotic Network (AERONET; Holben et al., 1998), the European project Cloudnet (Illingworth et al., 2007) and its descendant ACTRIS (Aerosols, Clouds, and Trace gases Research InfraStructure Network). At the ARM Oklahoma site, low stratiform clouds have been investigated in a variety of studies, from short-period field campaigns along with airborne and/or spaceborne measurements (Sassen et al., 1999; Dong et al., 
2002; Dong and Mace, 2003) to long-period climatologies (Lazarus et al., 2000; Sengupta et al., 2004; Dong et al., 2006; Xi et al., 2010). These studies concentrated on variations of liquid water path (LWP), cloud base height, cloud fraction, and cloud radiative forcing. Surprisingly, little attention is given to the interdependence between cloud macrophysical, microphysical and optical properties.

The relationship between cloud optical depth and droplet size is of particular interest, because their correlation patterns are highly related to the stages of warm cloud developments (Suzuki et al., 2010) and have been used for drizzle delineation (Nauss and Kokhanovsky, 2006; Suzuki et al., 2011). Using satellite and airborne observations, positive correlations have been observed in non-drizzling clouds and negative correlations in drizzling clouds (Nakajima et al., 1991; Nakajima and Nakajima, 1995; Kobayashi and Masuda, 2008), though negative correlations are not always significant (Harshvardhan et al., 2002).

Compared to ARM fixed sites, AERONET and ACTRIS have the advantage of widespread site locations in midlatitude continents, but these two networks are not necessarily as fully equipped as ARM sites. AERONET cloud-mode observations provide information on cloud optical depth and effective radius (Chiu et al., 2010, 2012), and therefore can be used to investigate the relationship between cloud microphysical and optical properties. ACTRIS provides sophisticated information on cloud boundary, water content and drizzle from active lidars and radars, which can be greatly enhanced by additional cloud optical depth retrievals to initiate the studies in the interdependence of cloud properties.

With enhancing observations of cloud optical depth in mind, this paper introduces a novel retrieval method for allsky clouds, using the previously untapped solar background light measured by ground-based lidars. Because the active laser pulse is rapidly attenuated in thick liquid clouds, lidar applications have been limited to optically thin clouds and not used to study stratiform clouds that frequently have optical depth greater than 3 . To alleviate this limitation, Chiu et al. (2007) retrieved optical depth of thick clouds using solar background light, received along with the active laser pulse but currently treated as the major source of noise in lidar applications (e.g. Campbell et al., 2002; Welton and Campbell, 2002; Dupont et al., 2011). However, since the relationship between solar background light and cloud optical depth is not monotonic (as explained in Sect. 2), Chiu et al. (2007) relied on prior knowledge of the cloud type and a manual discrimination process to provide retrievals for broken cloud scenes, an approach which is not ideal for long-term operations.

To address this issue, the aims of this paper are (1) to develop and evaluate an objective discrimination method that works in all-sky conditions; (2) to apply the new retrieval method to lidar measurements collected at the ARM Oklahoma site where ancillary data sets are available for intercomparisons; and, more importantly, (3) to investigate the interdependence of cloud macrophysical, microphysical and optical properties. Note that there is an obvious advantage to using an instrument with a narrow field of view (FOV), typically less than $1 \mathrm{mrad}$. Compared to conventional cloud optical depth retrieved from hemispheric-viewing radiometers, lidar provides properties of overhead clouds that potentially correlate better to liquid water paths retrieved from microwave radiometers that have a $6^{\circ}$ FOV. Additionally, the comparable $0.5^{\circ} \mathrm{FOV}$ of cloud radar, whose measurement is a good indicator of drizzle presence, significantly mitigates the issue of FOV mismatch when examining the interdependence of cloud properties for non-drizzling and drizzling clouds.

In Sect. 2, we review the retrieval principle and introduce the new discrimination method. In Sect. 3, we evaluate the performance of our new cloud optical depth against others retrieved from radiance and irradiance measurements. In Sect. 4, we characterise properties of stratiform clouds over the ARM Oklahoma site during 2005-2007, and examine the interdependence of cloud properties for non-drizzling and drizzling clouds. Finally, key findings and implications of this work are summarised in Sect. 5.

\section{Retrieval methodology}

Prior to July 2006, the micropulse lidar (MPL) at the ARM Oklahoma site was operated at a wavelength of $523 \mathrm{~nm}$ and provided unpolarized measurements at $30 \mathrm{~s}$ intervals. Since July 2006, the lidar operated at $532 \mathrm{~nm}$ with polarized measurements at $3-10 \mathrm{~s}$ temporal resolution. The FOV is $50 \mu \mathrm{rad}$. Solar background light is estimated from the averaged signal at lidar range gates between 45 and $55 \mathrm{~km}$, where the molecular backscatter is negligible, and is calibrated against principal plane measurements from AERONET to account for lidar filter degradation and window cleanliness.

Note that, for sites where collocated AERONET measurements are unavailable, one can calibrate solar background light by capitalising on the optical depth of thin clouds retrieved from active lidar signals. Specifically, radiance can be calculated through radiative transfer using thin cloud properties as input, and then be further used to calibrate the corresponding measured solar background light. Details of this alternative calibration approach can be found in Yang et al. (2008).

\subsection{Retrieving cloud optical depth from calibrated solar background light}

Solar background light received by a lidar is a function of cloud optical depth, cloud effective radius, cloud fraction, surface albedo and solar zenith angle. Figure 1a shows that calibrated solar background light increases with cloud optical depth for optically thin clouds due to increasing scattering of solar radiation into the FOV, and decreases for optically thick clouds due to increasing attenuation, resulting 

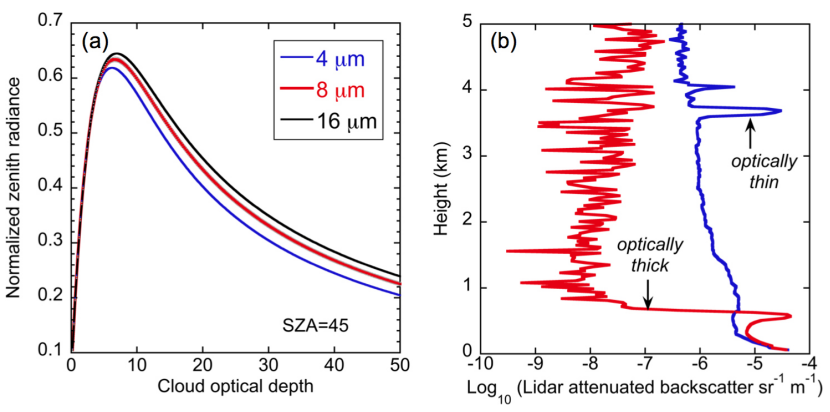

Figure 1. (a) Plot of calibrated solar background light in lidar measurements versus cloud optical depth at $523 \mathrm{~nm}$ wavelength and solar zenith angle (SZA) of $45^{\circ}$ for cloud effective radius of 4 , 8 and $16 \mu \mathrm{m}$. (b) Vertical profiles of logarithm (with base 10) lidar attenuated backscatter signals measured on 15 June 2007 at the ARM Oklahoma site at 19:00 UTC for optically thick clouds, and at 23:30 UTC for optically thin clouds.

in a non-monotonic relationship. For a given optical depth at lidar wavelengths, a larger effective radius and brighter surface will result in more observed solar background light. Since the FOV of lidars is small, the cloud cover for each profile is assumed to be either 0 for clear-sky or 1 for cloudy situations. This assumption is generally valid, although it becomes problematic near cloud edges when integrating signals from both clear and cloudy sky, which was particularly prevalent in early observations when the lidar integration time was $30 \mathrm{~s}$.

Cloud optical depth is retrieved by comparing the observed calibrated solar background light with lookup tables, computed from the discrete-ordinate-method radiative transfer model (DISORT; Stamnes et al., 1988) with an assumed cloud effective radius and surface albedo over a range of solar zenith angle up to $70^{\circ}$. We assume that cloud effective radius follows a normal distribution with a climatological mean (e.g. $8 \mu \mathrm{m}$ for the ARM Oklahoma site) and a standard deviation of $25 \%$ based on the uncertainty found in effective radius retrievals (cf. Tables 3 and 5 in Chiu et al., 2012). Surface albedo is estimated using collection 5 products from MODIS Terra/Aqua combined data at $500 \mathrm{~m}$ resolution with an uncertainty of $10 \%$ (Schaaf et al., 2002). We also include a $5 \%$ uncertainty in the calibrated solar background light, regarded as typical for radiance measurements (Holben et al., 1998). With the uncertainties for all input parameters defined, we perturb these parameters 40 times with values randomly drawn from normal distributions and retrieve cloud optical depth; the final cloud optical depth is reported as the mean and standard deviation of these 40 retrievals. The choice of 40 repetitions is arbitrary, but it affects retrievals insignificantly by $2 \%$ compared to results from 1000 repetitions (Chiu et al., 2012). The overall retrieval uncertainty in cloud optical depth is $\sim 10 \%$. Note that, with an uncertainty of $10 \%$ rather than $5 \%$ in calibrated solar background light, the overall retrieval uncertainty in cloud optical depth will increase to $17-25 \%$.

Since the relationship between zenith radiance and cloud optical depth is not monotonic, the aforementioned retrieval process results in two possible solutions at a given radiance: one corresponds to optically thin clouds, the other corresponds to optically thick. To remove this retrieval ambiguity, Chiu et al. (2007) applied a manual screening. Here we have developed an objective discrimination method using lidar backscatter measurements. We calibrated lidar backscatter signals in clear-air periods using the known molecular scattering at the lidar wavelength. Since the lidar energy was monitored and the lidar optics were assumed to not vary significantly, calibration coefficients from a suitable clear-air period were then extrapolated into cloudy periods. Figure $1 \mathrm{~b}$ shows an example of the vertical profiles of calibrated attenuated backscatter signals for optically thin and thick clouds. For thick clouds, the attenuated backscatter signal drops dramatically above the apparent cloud top; the mean logarithm (base 10) of the lidar signal from the cloud top to the layer $1 \mathrm{~km}$ above is around -7.5 . In contrast, for optically thin clouds, the mean logarithm value above cloud tops is around -6.0 . The difference between these two mean values is significant, suggesting that this parameter can be used to discriminate between optically thin and thick clouds; however, a proper threshold needs to be determined objectively, as described next. For convenience, the mean of the lidar attenuated backscatter signal from the apparent, or detectable, cloud top to the level $1 \mathrm{~km}$ above is denoted as $\beta_{\mathrm{ct}, 1 \mathrm{~km}}$ hereafter.

The threshold of $\beta_{\mathrm{ct}, 1 \mathrm{~km}}$ for discriminating cloud optical depth was determined through cases selected objectively using retrievals from shortwave narrowband irradiance measurements (Min and Harrison, 1996a, b), available in the ARM Archive. These cases represent clear or optically thin clouds, selected when the irradiance-based cloud optical depths were smaller than 5 for at least 60 consecutive minutes. The threshold of optical depth 5 was chosen because the zenith radiance typically peaks at this optical depth, and because the lidar signal tends to be completely attenuated beyond this value. For ARM unpolarized lidar measurements, Fig. 2 shows that $\beta_{\mathrm{ct}, 1 \mathrm{~km}}$ values range between -8.2 and -5.6 , and $94 \%$ of cases have values of $\beta_{\mathrm{ct}, 1 \mathrm{~km}}$ greater than -7.0. For ARM polarized measurements, the threshold $\beta_{\mathrm{ct}, 1 \mathrm{~km}}$ of -6.8 successfully captures a similar fraction $(95 \%)$ of clear-sky cases. Since this threshold does not vary much over time, we then used $\beta_{\mathrm{ct}, 1 \mathrm{~km}}$ thresholds of -7.0 and -6.8 for unpolarized and polarized measurements, respectively, throughout the entire analysis.

Finally, since our lookup tables were based on liquid water clouds, ice clouds were excluded using the lidar depolarization ratio and cloud base height. Based on 5-year groundbased lidar and radiosonde measurements, Naud et al. (2010) suggested a depolarization ratio threshold of $11 \%$ for differentiating ice from liquid. We found that this threshold 


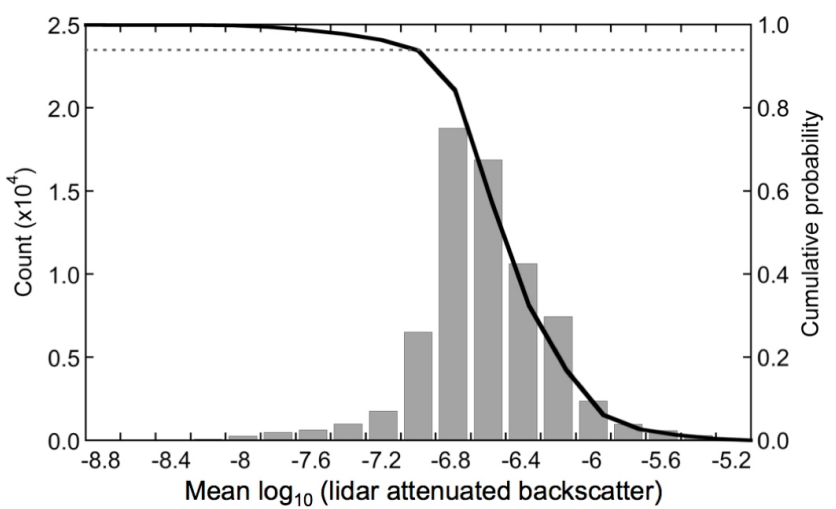

Figure 2. Histogram of $\beta_{\mathrm{ct}, 1 \mathrm{~km}}$ (the mean logarithm - with base 10 - lidar backscatter from the cloud top to $1 \mathrm{~km}$ above) and the corresponding cumulative probability (solid line) accounted from the larger end of $\beta_{\mathrm{ct}, 1 \mathrm{~km}}$ for clear sky at the ARM Oklahoma site in 2005. The dashed line represents the $94 \%$ cumulative probability.

generally worked well, but occasionally missed ice clouds when cloud bases were high or clouds were not sufficiently thick. To mitigate these issues, a second criterion involving cloud base height was applied. Based on airborne lidar measurements, Hogan et al. (2004) conducted a global investigation of stratiform supercooled liquid water clouds and showed that less than $10 \%$ of supercooled liquid water clouds occurred at temperatures colder than $-20^{\circ} \mathrm{C}$. This temperature threshold approximately corresponds to an altitude of $7 \mathrm{~km}$ at the ARM Oklahoma site during summer seasons; any clouds located higher than $7 \mathrm{~km}$ were excluded and not retrieved in this study. When lidar depolarization ratio was not available, we used merged sounding data and excluded cases with apparent cloud tops (identified by lidar) above the freezing level. Note that these exclusion criteria are simple yet imperfect, particularly when clouds are thick and lidar cannot detect the true cloud top. Therefore, we further excluded time periods when $1 \mathrm{~min}$ ice water paths (IWPs) were greater than zero, based on retrievals from the Cloudnet algorithm that uses empirical relationships between ice water content, radar reflectivity and temperature (Hogan et al., 2006).

\subsection{Calculating cloud effective radius and discriminating drizzling clouds}

Once cloud optical depth is retrieved, cloud effective radius can be estimated by combining liquid water paths (LWPs) with two commonly used approaches. The first assumes a constant effective radius in the vertical (Stephens, 1978), and the second assumes a constant cloud droplet number concentration and a linear increase of liquid water content in the vertical (Wood and Hartmann, 2006). Using simultaneous retrievals of cloud optical depth and effective radius at the ARM Oklahoma site, Chiu et al. (2012) found that the second assumption led to a better agreement with LWP mea- sured by microwave radiometers (MWRs) in all sky conditions. Thus, we estimated cloud effective radius $r_{\text {eff }}$ by

$r_{\mathrm{eff}}=\frac{9}{5} \cdot \frac{\mathrm{LWP}}{\rho_{\mathrm{w}} \tau}$,

where $\rho_{\mathrm{w}}$ is the density of water, and $\tau$ is cloud optical depth. LWP retrievals are available in the ARM Archive MWRRET product with an uncertainty of $20-30 \mathrm{~g} \mathrm{~m}^{-2}$ and a $20 \mathrm{~s}$ time resolution, based on Turner et al. (2007) using two-channel microwave radiometers.

To investigate how the interdependence of cloud macrophysical and microphysical properties on $\tau$ differs between non-drizzling and drizzling clouds, we used the ARM Active Remotely Sensed Clouds Locations (ARSCL; Clothiaux et al., 2000) product for estimating cloud geometric thickness and for diagnosing drizzling clouds. Combining measurements of cloud radar, micropulse lidar, and ceilometer, ARSCL provides cloud boundary heights and reflectivity at $10 \mathrm{~s}$ resolution and $45 \mathrm{~m}$ vertical resolution. Cloud geometric thickness was derived from the lowest cloud base (typically detected by lidar) and the cloud top height (detected by radar). We restrict our analysis to single-layer warm clouds by selecting cases with geometrical thicknesses less than $1.5 \mathrm{~km}$, minimising cases of multilayer precipitating clouds that are hard to separate by radar reflectivity and could be erroneously identified as a single-layer cloud. When clouds were sufficiently thick and no significant radar returns were detected, no valid geometric thickness could be obtained and thus such clouds were omitted in our analysis.

Additionally, drizzle discrimination was based on radar reflectivity $(Z)$ at the lowest cloud base. Similar to Suzuki et al. (2011), we identify clouds as "non-drizzling" if $Z$ is less than $-15 \mathrm{dBZ}$, and "drizzling" if $Z$ is greater than $-15 \mathrm{dBZ}$. According to the relationship $R=0.0788 \times Z^{0.75}$ (rain rate $R$ in $\mathrm{mm} \mathrm{h}^{-1}$ and $Z$ in $\mathrm{mm}^{6} \mathrm{~m}^{-3}$ ) derived from data in Mann et al. (2014), this threshold of $-15 \mathrm{dBZ}$ corresponds to $\sim 0.006 \mathrm{~mm} \mathrm{~h}^{-1}$.

\section{Evaluation of optical depth retrievals}

We evaluate our retrievals against a number of benchmarks. The first benchmark is retrievals using zenith radiances from AERONET cloud-mode observations that provide unambiguous cloud optical depth by capitalising on the surface reflectance contrast between 440 and $870 \mathrm{~nm}$ wavelengths (Chiu et al., 2010). This benchmark works for all-sky conditions, but retrievals are available only when clouds block the Sun, so AERONET sun photometers operate in cloud mode rather than normal aerosol mode. Cloud-mode retrievals (level 1.5) are available on the AERONET web page.

The second benchmark is retrievals from irradiance measurements at $20 \mathrm{~s}$ temporal resolution, available in the ARM Archive. This method uses direct and diffuse transmittance at $415 \mathrm{~nm}$ to estimate cloud optical depth with a default 


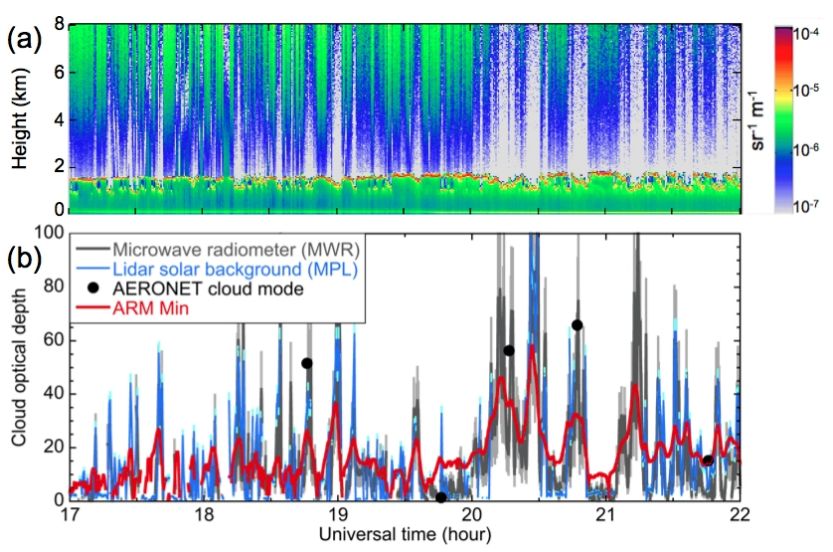

Figure 3. (a) Attenuated backscatter signals from micropulse lidar on 19 April 2005. (b) Time series of cloud optical depth retrieved from a microwave radiometer (MWR), lidar solar background signals from micropulse lidar (MPL), AERONET cloud-mode observations, and ARM Min product (using narrowband irradiance measurements). MWR-based retrievals (grey lines) are based on an assumed cloud effective radius of $8 \mu \mathrm{m}$; grey error bars denote lower and upper limits for MWR values, corresponding to a change in droplet effective radius from 6 to $14 \mu \mathrm{m}$.

effective radius of $8 \mu \mathrm{m}$ (Min and Harrison, 1996a). With additional LWP retrievals from MWRs, the estimated optical depth and initial effective radius are updated iteratively by minimizing least-squares errors in radiance along with an adjoint radiative transfer method (Min and Harrison, 1996b; Min et al., 2003). Because irradiances are measured from a hemispheric FOV, this method works best for relatively overcast homogenous clouds. For convenience, we refer to retrievals from the second benchmark as the ARM Min product hereafter.

The third benchmark is retrievals using LWP in the ARM Archive MWRRET product (see Sect. 2.2) and Eq. (1) with an assumed effective radius of $8 \mu \mathrm{m}$, a typical value for the Oklahoma site (Kim et al., 2003). However, since the true cloud effective radius is not necessarily $8 \mu \mathrm{m}$, we further estimate the potential range of cloud optical depth by varying effective radius from 6 to $14 \mu \mathrm{m}$. Clearly, retrieval comparison to the third benchmark is intended to qualitatively evaluate cloud optical depth variations, rather than a quantitative measure.

In Sect. 3.1, we present intercomparison results from case studies, including broken cloud and overcast cloud scenes. Additionally, since irradiance-based retrievals work best for homogenous scenes, we focus on overcast stratiform clouds during the period 2005-2007 in Sect. 3.2.

\subsection{Case study}

Figure 3 shows time series of lidar backscatter signals and cloud optical depths on 19 April 2005 at the ARM Oklahoma site. The penetrated signal at 17:00 UTC and the completely

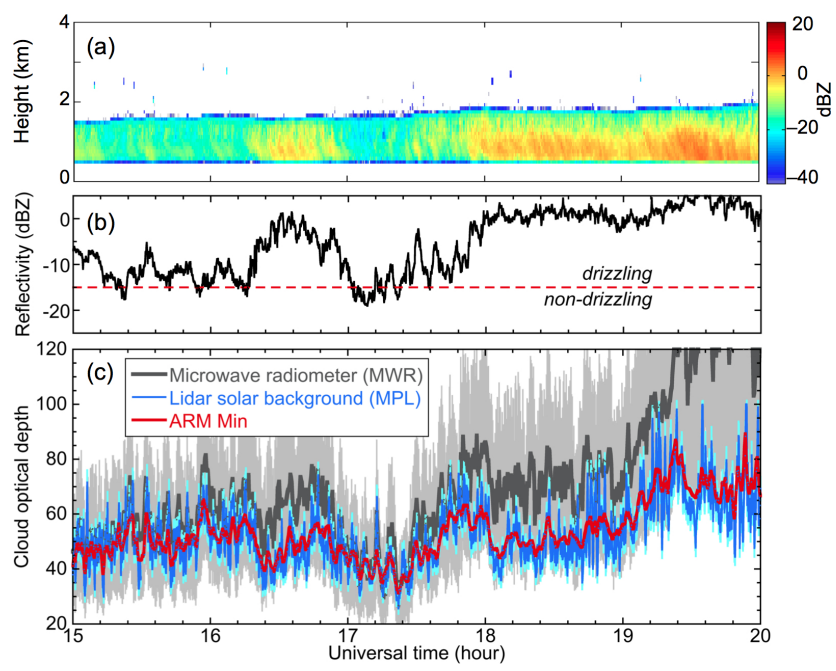

Figure 4. (a) Time series of radar reflectivity profiles on 10 April 2007. (b) Cloud-base reflectivity indicating the presence of drizzle. (c) Time series of cloud optical depth retrieved from a microwave radiometer (MWR), lidar solar background signals from micropulse lidar (MPL) and ARM Archive Min retrievals. Grey error bars denote lower and upper limits for MWR values, corresponding to a change in droplet effective radius from 6 to $14 \mu \mathrm{m}$. Note that AERONET cloud-mode observations were unavailable for this day.

attenuated signal at 20:30 UTC indicate the presence of clearsky and thick clouds, respectively. These indications of cloud presence by active lidar signals in Fig. 3a correspond well to optical depth retrievals in Fig. 3b. Figure 3b also shows that retrievals from calibrated lidar solar background light agree with those from AERONET cloud mode and from microwave observations for intermittent and broken cloud situations between 17:00 and 18:00 UTC.

Examining two more cases on 10 April and 2 May 2007 when both non-drizzling and drizzling periods are apparent, Figs. 4 and 5 show consistent agreements between our retrievals and the benchmark retrievals. Note that $\sim 20 \%$ of clouds between 14:00 and 18:00 UTC in Fig. 5 are multilayered. Since drizzle classification is based on cloud-base reflectivity, these multilayer clouds are excluded in the following analyses to ensure that LWP, geometric thickness, optical depth and drizzling characteristics refer to the same lowest cloud layer. In short, the overall agreement between independent retrievals suggests that the calibration of solar background light and the newly developed method for distinguishing thin and thick clouds work well for all-sky conditions.

\subsection{Stratiform clouds during the period 2005-2007}

This section reports results of intercomparison between retrievals from lidar solar background, AERONET cloudmode observations, and from narrowband irradiance measurements for relatively homogenous and overcast cloud 


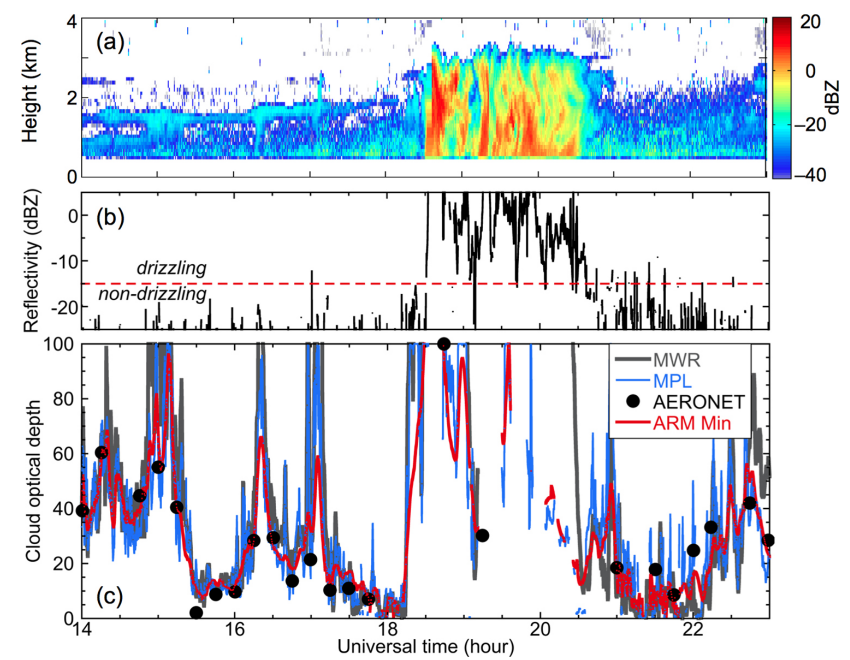

Figure 5. Same as Fig. 4, but for 2 May 2007. Heavy precipitation occurs at 18:30-20:30 UTC.

cases. To objectively select appropriate low-level stratiform water clouds, combined measurements from cloud radar, micropulse lidar, and ceilometer in the ARSCL product were used to identify $1 \mathrm{~h}$ time periods with cloud fraction greater than 0.95 and cloud top heights lower than $5 \mathrm{~km}$. Since our analysis includes several data sets at various temporal resolutions, we average data points over a 1 min time period. We took a simple linear average for LWP retrievals and radar reflectivity, but used a logarithm averaging technique for lidarbased cloud optical depth because transmittance is a concave function of cloud optical depth. In other words, we averaged the natural logarithm of cloud optical depth, and then transformed the average back to obtain the 1 min mean. Additionally, to use the same data set for investigating interdependence of cloud macrophysical, microphysical and optical properties in Sect. 4, we further excluded time periods if the effective radius was outside the range between 3 and $100 \mu \mathrm{m}$. This exclusion process led to a final sample size of $5200 \mathrm{~min}$ of data points during the period 2005-2007 that represents $\sim 35 \%$ of daytime stratiform cases.

Figure 6 shows histograms of 1 min averaged cloud optical depth and a scatter plot of retrievals from lidar solar background signals against those from flux measurements. Both data sets reveal an occurrence peak at optical depth of 15-20, but an evident discrepancy occurs in the optical depth bin of 0-5. The reason for the lack of small optical depth in lidar-based retrievals is partly because their corresponding LWP values have always been zero or negative and therefore are excluded, implying that it remains challenging for twochannel microwave radiometers to detect very optically thin clouds.

The mean cloud optical depth from lidar measurements is 35 , larger than that retrieved from irradiances by two optical depths. A high correlation coefficient of 0.94 is obtained, as
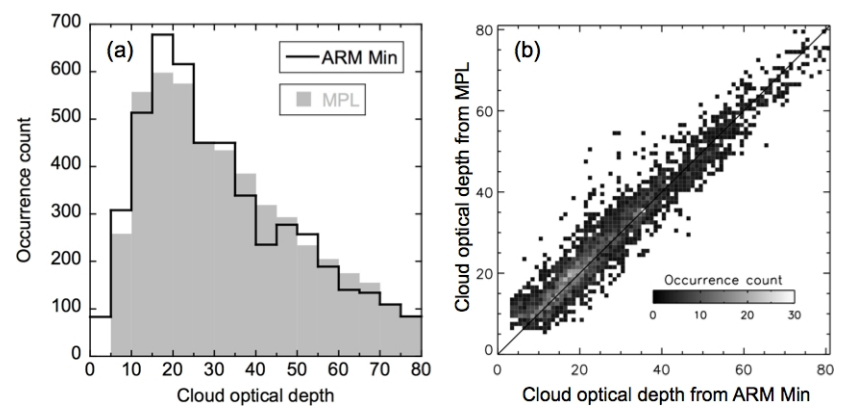

Figure 6. (a) Histograms of occurrence count and (b) a scatter plot for intercomparison of cloud optical depths retrieved from solar background signals received by micropulse lidar (MPL) and those from the ARM Min product. Colours represent the number of occurrence count, and the black solid line represent the $1: 1$ line.

shown by the majority of data points in Fig. 6b lying close to the $1: 1$ line. In addition, the root-mean-squared difference between the two is 8 ( $24 \%$ relative to the mean of irradiancebased retrievals), partly attributed to cases that have much larger lidar-based retrievals than those from irradiances. Particularly for cases where irradiance-based retrievals are less than 5, we have found that these points are associated with intermittent cloudy conditions having LWP between -10 and $80 \mathrm{~g} \mathrm{~m}^{-2}$. Therefore, the discrepancy in cloud optical depth for these data points is likely because lidar has a narrow FOV to capture larger variations that tend to be smeared out in irradiance-based retrievals due to a hemispheric FOV of shadowband radiometers.

Similarly, Fig. 7 shows a scatter plot for evaluating retrievals against the AERONET cloud-mode product. The mean cloud optical depth from lidar measurements is 30 , smaller than cloud-mode retrievals by three optical depths. The correlation coefficient is 0.95 , while the root-meansquared difference between the two is 8 ( $24 \%$ relative to the mean of cloud-mode retrievals).

\section{Interdependence of stratiform cloud properties}

\subsection{Macrophysical properties versus optical depth}

Using the same stratiform cloud cases shown above, we investigate how cloud macrophysical and microphysical properties vary with optical depth in non-drizzling and drizzling stratiform clouds, categorised by a reflectivity threshold of $-15 \mathrm{dBZ}$ as described in Sect. 2.2. Figure 8a shows that nondrizzling clouds occur more frequently at optical depths of 10-20, while drizzling clouds have a relatively uniform frequency distribution throughout the entire optical depth range. Using an adiabatic cloud model for non-drizzling clouds, Boers and Mitchell (1994) showed that LWP, cloud geometric thickness $H$ and optical depth $\tau$ follow LWP $\propto H^{2}, \tau \propto$ $H^{5 / 3}$, and thus LWP $\propto \tau^{6 / 5}$. Not surprisingly, Fig. 8b shows 


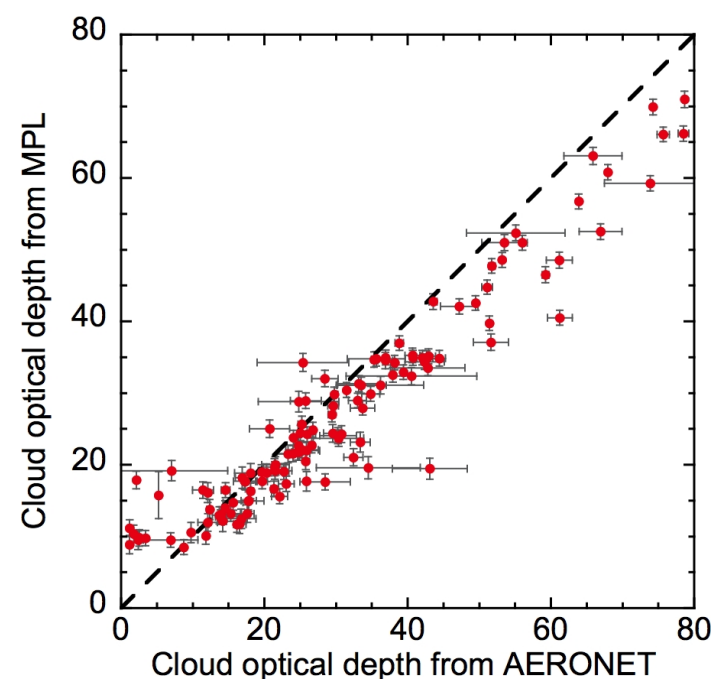

Figure 7. Scatter plot for intercomparison of cloud optical depths retrieved from solar background signals received by micropulse lidar (MPL) and those from the AERONET cloud-mode product. The error bars represent 1 standard deviation of retrievals, while the black dashed line represents the $1: 1$ line.

that LWP indeed increases approximately linearly with $\tau$ for both cloud categories. LWP in non-drizzling clouds is proportional to $\tau^{1.09 \pm 0.01}$ with $95 \%$ confidence intervals; the exponent is slightly smaller than the predicted value of 1.2 under an adiabatic assumption. LWP in drizzling clouds is generally $20-40 \%$ larger than those in non-drizzling clouds.

Similar to LWP, Fig. 8c shows that $H$ also increases with $\tau$. Using $1 \mathrm{~min}$ averaged ARM data from these stratiform cloud cases, the relationship between $H$ (in metres) and $\tau$ can be approximated by

$H=(308 \pm 15) \cdot \tau^{0.25 \pm 0.01}$ for non-drizzling clouds,

$H=(513 \pm 51) \cdot \tau^{0.16 \pm 0.03}$ for drizzling clouds,

corresponding to correlation coefficients of 0.95 and 0.79 , respectively. These relationships indicate that the geometric thickness in drizzling clouds is at least $10 \%$ larger than that in non-drizzling clouds at a given $\tau$. We have also found that these relationships vary little when taking hourly means rather than $1 \mathrm{~min}$ averages. Using the adiabatic approximation as explained above, the exponents in non-drizzling and drizzling clouds from ARM data are both much smaller than the predicted value of 0.6 .

Cloud geometric thickness derived from Eqs. (2) and (3) is compared to the results for marine stratocumulus off the coast of California during the First ISCCP Regional Experiment. Based on Minnis et al. (1992), their relationship between $H$ and $\tau$ can be re-written as the following:

$H=58 \cdot \tau^{0.56}$,

where $H$ was retrieved from hourly averaged surface ceilometer and acoustic sounder measurements; $\tau$ was esti-
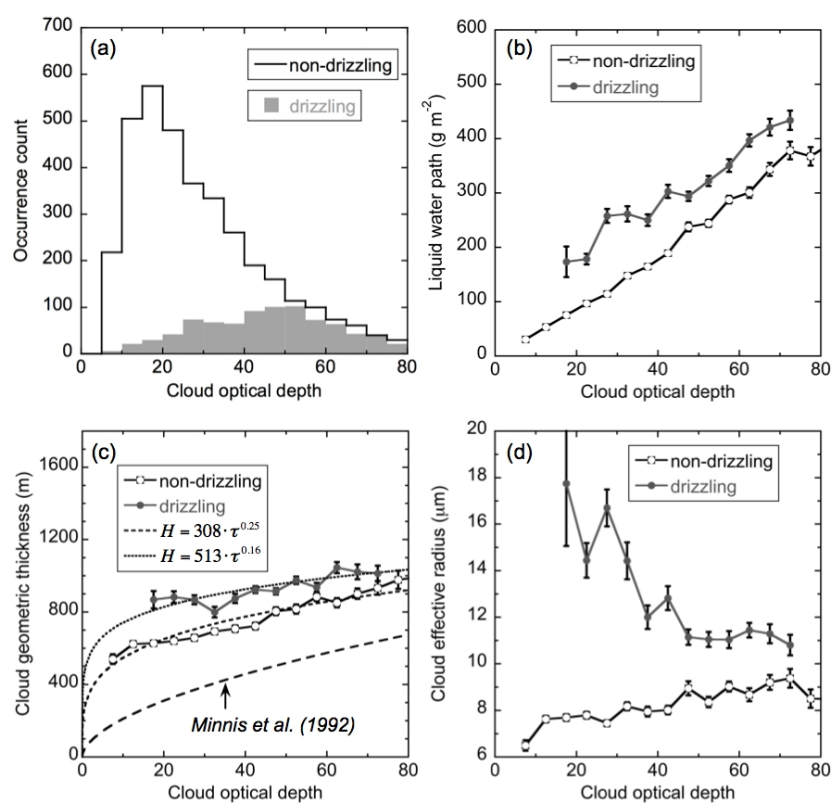

Figure 8. (a) Occurrence histogram of cloud optical depth $(\tau)$; plots of (b) liquid water path, (c) geometric thickness ( $H$ in metres) of cloud layer and (d) cloud effective radius versus optical depth for low-level stratiform clouds, using $1 \mathrm{~min}$ averaged retrievals at the ARM Oklahoma site during the period 2005-2007. A cloud-base radar reflectivity threshold of $-15 \mathrm{dBZ}$ is used for drizzle classification; a cloud is drizzling if its cloud-base reflectivity exceeds the threshold, otherwise, non-drizzling. Error bars represent 1 standard error. Three power-law relationships are co-plotted in (c); dotted lines are based on ARM data, while the dashed line is adapted from the satellite-based finding reported in Minnis et al. (1992). (b-d) omit bins of cloud optical depth with a sample size smaller than 25 .

mated from Geostationary Operational Environmental Satellite visible and infrared radiances. The relationships obtained here suggest that the geometric thicknesses in continental stratiform clouds can be thicker than marine stratocumulus by at least $35 \%$ for cloud optical depths less than 80 .

\subsection{Cloud effective radius versus optical depth}

Unlike LWP and $H$, Fig. 8d shows that cloud effective radius has a different dependence on optical depth between nondrizzling and drizzling clouds. The strong positive correlation of 0.8 between cloud effective radius and optical depth in non-drizzling clouds is consistent with many studies using airborne and spaceborne remote sensing measurements (e.g. Han et al., 1994; Nakajima and Nakajima, 1995; Harshvardhan et al., 2002), but the asymptotic radius from the ARM data is $\sim 10 \mu \mathrm{m}$, smaller than the so-called critical radius $(\sim 15 \mu \mathrm{m})$ reported in literature for marine low clouds (Nakajima and Nakajima, 1995; Kobayashi and Masuda, 2008; Painemal and Zuidema, 2011). Additionally, these non-drizzling clouds show $r_{\text {eff }}$ proportional to $\tau^{0.11 \pm 0.01}$. The exponent of 0.11 is smaller than the value of 0.2 derived 

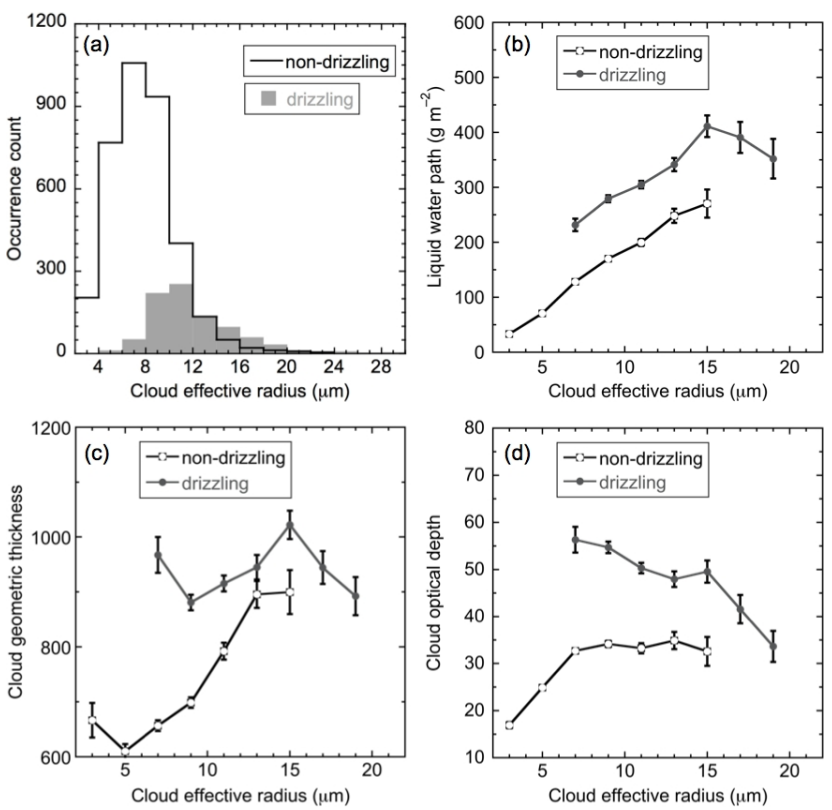

Figure 9. Same as Fig. 8, but with plots of cloud properties versus cloud effective radius. (b-d) omit bins of cloud effective radius with a sample size smaller than 25 .

from satellite and aircraft measurements for the eastern Pacific stratocumulus (Szczodrak et al., 2001), and the theoretical value of 0.2 derived under the assumption of adiabatic and constant cloud droplet number concentration $N_{\mathrm{d}}$ (Lohmann et al., 2000), meaning that the condition at the ARM Oklahoma site may be slightly sub-adiabatic, and/or that $N_{\mathrm{d}}$ variation with height is not negligible.

For drizzling clouds, Nakajima and Nakajima (1995) showed that cloud effective radius decreased from 20 to $10 \mu \mathrm{m}$ with an increase in $\tau$ from 5 to 20 . Similarly, our result shows a negative correlation $(-0.75)$ with a $99 \%$ confidence level for drizzling clouds. The negative correlations between cloud effective radius and optical depth in drizzling clouds can be explained by precipitation influence, which possibly reduces cloud optical depth through the removal of droplets (Boers and Rotstayn, 2001). Further analyses reveal that a number of drizzling clouds with small optical depths indeed have large effective radii greater than $50 \mu \mathrm{m}$, often found at the end of a precipitation system passing over. These cases, however, occurred less frequently compared to those with small effective radii, resulting in the mean cloud effective radii fluctuating between 12 and $18 \mu \mathrm{m}$ with large standard errors at small optical depths.

Since the correlation between $\tau$ and $r_{\text {eff }}$ is positive in nondrizzling clouds but negative in drizzling clouds, the difference in $r_{\text {eff }}$ between two types of clouds decreases with increasing cloud optical depth, which is a result of Fig. 8b. Across all optical depth bins, Fig. 8b shows that LWP in drizzling clouds is consistently $\sim 85 \mathrm{~g} \mathrm{~m}^{-2}$ larger than that in non-drizzling clouds. Compared to cases with small $\tau$, this
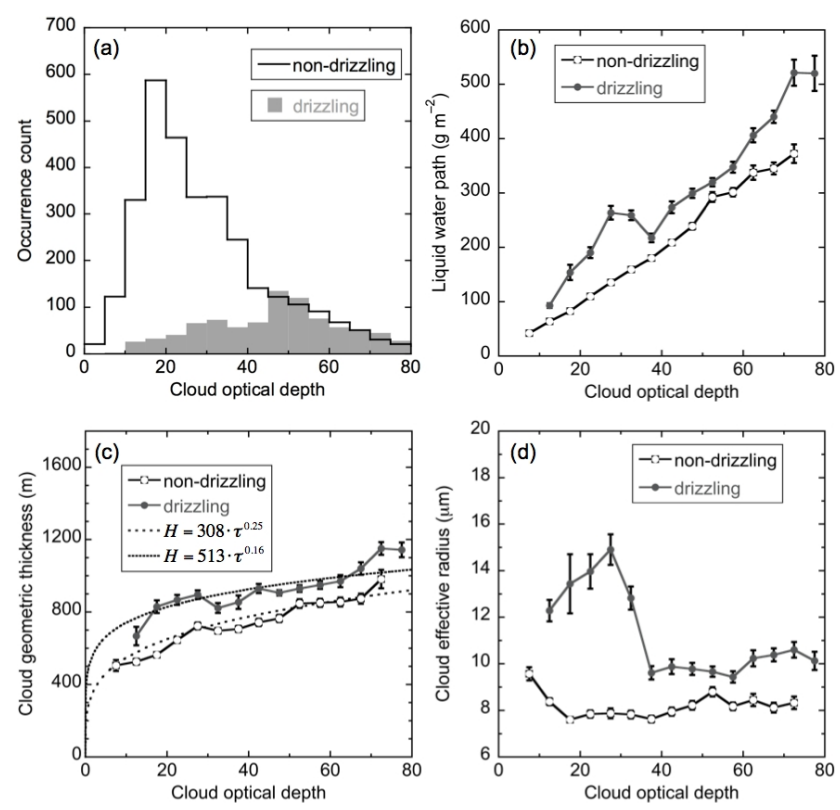

Figure 10. Same as Fig. 8 but using cloud optical depths from the ARM Archive Min product. Note that the power-law relationships between cloud geometric thickness and optical depth by dashed and dotted lines in (c) are derived from data in Fig. 8 for visual comparisons.

extra LWP in drizzling clouds distributes to more droplets in cases with large $\tau$, leading to a smaller increase in $r_{\text {eff }}$ (as shown in Eq. (1) having a denominator $\tau$ ).

In short, the difference between non-drizzling and drizzling clouds at a given cloud optical depth mainly ranges between 2 and $7 \mu \mathrm{m}$ with a mean of $5 \mu \mathrm{m}$ (Fig. 8d), similar to the finding from satellite observations in marine stratocumulus (Kubar et al., 2009). This mean size difference between two cloud categories is clear in Fig. 9a, showing that the distribution of non-drizzling clouds peaks at $6-8 \mu \mathrm{m}$, with a mean of $8 \mu \mathrm{m}$, and the distribution of drizzling clouds peaks at $10-12 \mu \mathrm{m}$, with a mean of $13 \mu \mathrm{m}$.

\subsection{Interdependence derived from the ARM Min product}

To examine whether this interdependence is sensitive to the choice of cloud optical depth product, we repeated the same analysis using the ARM Min product as shown in Fig. 10. Firstly, similar to results derived from lidar-based retrievals, LWP in non-drizzling clouds is proportional to $\tau^{1.01 \pm 0.01}$ with $95 \%$ confidence intervals. LWP in drizzling clouds are also larger than those in non-drizzling clouds, although the difference between the two varies in a larger range between 30 and $150 \mathrm{~g} \mathrm{~m}^{-2}$. Secondly, cloud geometric thickness can be approximated by

$$
\begin{aligned}
& H=(249 \pm 12) \cdot \tau^{0.30 \pm 0.01} \text { for non-drizzling clouds, } \\
& H=(447 \pm 33) \cdot \tau^{0.20 \pm 0.02} \text { for drizzling clouds. }
\end{aligned}
$$


Although the exponents and prefactors of Eqs. (5) and (6) are different from Eqs. (2) and (3), the geometric thicknesses derived from the ARM Min and lidar-based retrievals are similar, as shown in Fig. 10c. Finally, while the negative correlation between $\tau$ and $r_{\text {eff }}$ in drizzling clouds holds in Fig. 10d, the more robust positive correlation in non-drizzling clouds, found in Fig. 8d and satellite observations, disappears due to a relatively flat $r_{\text {eff }}$ of $\sim 8 \mu \mathrm{m}$ across all optical depth bins.

In short, the relationships of LWP and $H$ with $\tau$ are not sensitive to the choice of cloud optical depth product, but this is not true for the correlation between $\tau$ and $r_{\text {eff. This high- }}$ lights the potential importance of having comparable FOVs among various instruments for investigating $\tau-r_{\text {eff }}$ correlation, although properly addressing this issue may require more thorough simulation experiments.

\subsection{Implication on drizzle delineation}

Taking a different view, now we use the same data set as shown in Fig. 8 to investigate how LWP, $H$ and $\tau$ vary with $r_{\text {eff. }}$. Figure $9 \mathrm{~b}-\mathrm{d}$ shows that properties between non-drizzling and drizzling clouds differ the most in the $r_{\text {eff }}$ range of 7$11 \mu \mathrm{m}$, although this could be a result of a relatively smaller sample size outside this $r_{\text {eff }}$ range. Specifically, Fig. 9d shows that optical depth of non-drizzling clouds increases with $r_{\text {eff }}$ and changes little at $r_{\text {eff }}$ beyond $7 \mu \mathrm{m}$. The relatively small change in $\tau$ is also found in the $r_{\text {eff }}$ range of $7-15 \mu \mathrm{m}$ for drizzling clouds; this is similar to the finding in satellite observations (Kobayashi and Masuda, 2008), but their data showed such behaviour only when $r_{\text {eff }}$ was larger than a critical value of $\sim 15 \mu \mathrm{m}$. Since Kobayashi and Masuda (2008) used 21 day measurements from the Tropical Rainfall Measuring Mission satellite and sampled tropical marine warm clouds, the difference in the critical effective radius (7 vs. $15 \mu \mathrm{m})$ may be due to the regional variability of precipitating clouds. Additionally, the definition of this critical effective radius is rather loose, and its value can strongly depend on how and at which altitude cloud effective radii were estimated. The difference in the resulting critical value of effective radius between airborne/spaceborne measurements and the ARM data can be partly due to the fact that retrievals from the former is mainly determined by droplets at cloud tops, while the latter is determined by the entire cloud layer (Platnick, 2000; Chiu et al., 2012).

Results from Figs. 8d and 9d imply that it is plausible to delineate drizzling clouds using a simple threshold; for example, we can roughly classify clouds as drizzling when cloud effective radius exceeds a critical value $r^{*}$ of $10 \mu \mathrm{m}$ (Fig. 8d) or when cloud optical depth exceeds 40 (Fig. 9d). Similarly, based on satellite retrievals and groundbased radar measurements, Nauss and Kokhanovsky (2006) proposed a more sophisticated delineation function, given as

$r^{*}=\frac{A}{\tau}$,
Table 1. Contingency table used to evaluate drizzle delineation methods. A-D represent the number of hits, false alarms, misses and correct negatives, respectively.

\begin{tabular}{lcc}
\hline & \multicolumn{2}{c}{ Reference observations } \\
\hline New method & Yes & No \\
Yes & $A$ & $B$ \\
No & $C$ & $D$ \\
\hline
\end{tabular}

where coefficient $A$ is $920 \mu \mathrm{m}$ and the critical value $r^{*}$ varies with cloud optical depth $\tau$. To evaluate how well these methods discriminate between non-drizzling and drizzling clouds (i.e. a binary classification), we computed the Heidke skill score (HSS) from a contingency table (Table 1), defined as

$\mathrm{HSS}=\frac{2(A \cdot D-B \cdot C)}{(A+C)(C+D)+(A+B)(B+D)}$.

HSS not only measures the proportion of correct classifications (including both correct hits and negatives), but more importantly, also takes into account the expected skill obtained by chance in the absence of any skill (Barnston, 1992). In general, an HSS of 0 indicates no skill, while 1 represents perfect skill.

Figure 11 summarises HSS using three different methods. Firstly, using a simple fixed cloud effective radius as the delineation threshold (red lines), the optimal threshold that maximises HSS is $10 \mu \mathrm{m}$, agreeing with results in Fig. 8d. Secondly, applying a fixed threshold of cloud optical depth (blue lines), the optimal threshold is $\sim 42$ and HSS is similar in the optical depth range between 40 and 45 . Note that the maximum of HSS using the optimal optical depth threshold is not as good as that from an effective radius threshold of $10 \mu \mathrm{m}$. Thirdly, a dynamic threshold of cloud effective radius derived by Eq. (7) apparently yields a higher HSS ( $\sim 0.52)$, compared to the previous two simple methods; the optimal coefficient $A$ is $380 \mu \mathrm{m}$, rather than $920 \mu \mathrm{m}$ found in satellite observations (Nauss and Kokhanovsky, 2006) for convective systems over central Europe taken during the extreme summer floods in 2002. It is expected that the coefficient $A$ varies with cloud type, site location, and more importantly, the threshold of rain rate used to define drizzle $\left(\sim 0.006 \mathrm{~mm} \mathrm{~h}^{-1}\right.$ in our cases).

Since HSS is dependent on the frequency of occurrence of an event, we further test our delineation thresholds using the symmetric extremal dependence index (SEDI), which is independent of occurrence frequency and thus works for both common and rare events (Ferro and Stephenson, 2011). SEDI is defined as

$\mathrm{SEDI}=\frac{\ln F-\ln H+\ln (1-H)-\ln (1-F)}{\ln F+\ln H+\ln (1-H)+\ln (1-F)}$,

where

$H=\frac{A}{A+C}$ and $F=\frac{B}{B+D}$. 


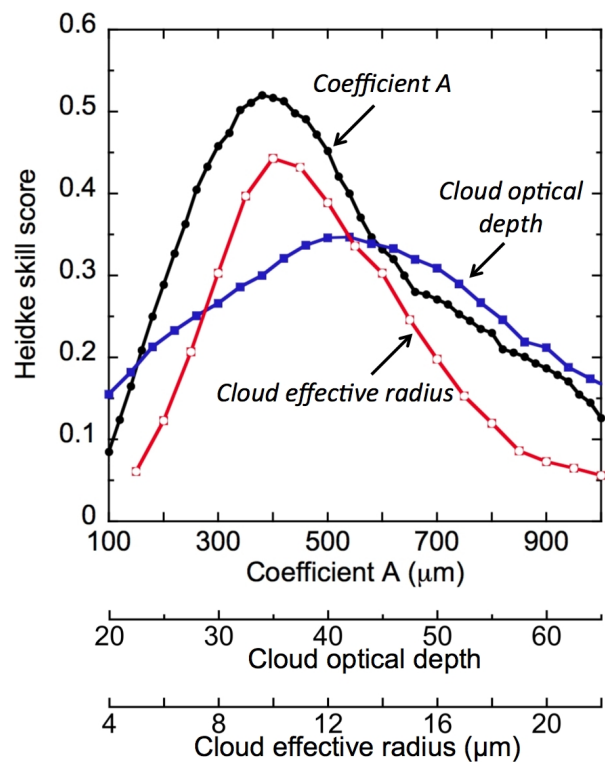

Figure 11. Heidke skill scores for three drizzle delineation methods. The first (red) uses cloud effective radius as delineation threshold, while the second (blue) uses cloud optical depth instead. The third (black) uses a dynamic threshold as a function of both cloud optical depth and effective radius with a coefficient $A$ (see Eq. (7) in text for details).

Similar to HSS, a SEDI value of 0 indicates no skill, while 1 represents perfect skill. As Fig. 12 shows, the optimal cloud effective radius and cloud optical depth thresholds are $\sim 10 \mu \mathrm{m}$ and $\sim 40$, respectively. When considering a dynamic threshold, the optimal coefficient $A$ of $340 \mu \mathrm{m}$ is found. Overall, the optimal thresholds from SEDI are similar to those derived from HSS.

In short, depending on the availability of measurements, one can use a cloud optical depth of 40 as the simplest way for drizzle delineation in the absence of LWP and radar measurements, although this threshold may depend on ambient aerosol loading. If co-incident LWP measurements are available, the dynamic threshold of cloud effective radius given in Eq. (7) with a coefficient $A$ of $340-380 \mu \mathrm{m}$ is a better approach to delineating drizzle for mid-latitude continental stratiform clouds.

\section{Summary}

To better represent clouds in weather and climate models, long-term global measurements can provide direct constraints and improve our knowledge of cloud and precipitation formation, and their interactions with radiation and aerosol. In particular, low warm clouds strongly influence global climate through their impacts on Earth's radiation and water energy cycle. While marine low clouds have been extensively studied, continental warm clouds received rela-

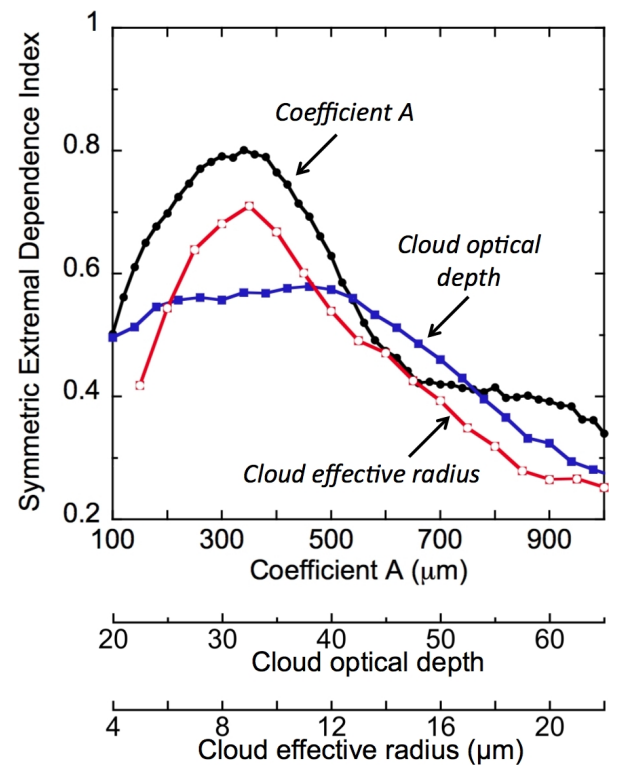

Figure 12. Same as Fig. 11, but using the symmetric extremal dependence index to optimise thresholds for drizzle delineation.

tively little attention partly due to the fact that the majority of satellite retrievals work best over oceans.

Using ground-based measurements at the ARM Oklahoma site during the period 2005-2007, we conducted an extensive analysis for mid-latitude continental low-level clouds. To retrieve cloud optical depth, we developed a novel method that capitalised on unexploited solar background light that is currently treated as noise and has largely inhibited lidar applications in all-sky conditions and during daytime. This new technique works well; when compared to other benchmarks, the mean bias of cloud optical depth is around 2 and the rootmean-squared difference is 8 ( $24 \%$ relative to the mean optical depth). Since lidars have a FOV much closer to those of microwave radiometers than conventional hemisphericviewing radiometers, it is more appealing to use lidar-based cloud retrievals to understand the linkage between cloud macrophysical, microphysical and optical properties.

A number of key features are found in the relationships between LWP, geometric thickness $H$, droplet effective radius $r_{\text {eff }}$ and cloud optical depth $\tau$. Firstly, LWP and $H$ follow a power-law relationship with positive exponents with $\tau$; LWP and $H$ in drizzling clouds are generally $20-40 \%$ and at least $10 \%$ higher than those in non-drizzling clouds, respectively. Similar to LWP, $r_{\text {eff }}$ also increases with $\tau$ following a power law for non-drizzling clouds, but this does not hold for drizzling clouds. In the presence of drizzle, a negative correlation is found between $r_{\text {eff }}$ and $\tau ; r_{\text {eff }}$ also tends to be $5 \mu \mathrm{m}$ larger than droplet sizes in non-drizzling clouds.

While several aircraft and satellite observations have suggested that $r_{\text {eff }}$ of the order of $15 \mu \mathrm{m}$ may be a good indicator to distinguish between non-drizzling and drizzling marine clouds, we found that a threshold of $\sim 10 \mu \mathrm{m}$ works better 
for ground-based observations. The difference in threshold between various observational platforms is likely attributed to the fact that satellite retrievals are mainly determined by properties at cloud tops and, conversely, ground-based retrievals utilise the full cloud profile. If co-incident LWP measurements are available, a dynamic threshold of cloud effective radius given in Eq. (7) with a coefficient $A$ of 340$380 \mu \mathrm{m}$ is a better approach to delineating drizzle for midlatitude continental stratiform clouds.

We have demonstrated a novel retrieval method using untapped solar background signals in lidar measurements, which greatly extends lidar applications from cirrus to all types of clouds, and provides a new approach to distinguishing between non-drizzling and drizzling clouds. With collocated radar and LWP measurements, the new retrieval can also be used to compare and contrast drizzle and drizzle-free cloud properties. This new method can be easily adapted to the exiting lidar networks if collocated sun photometer measurements are available, including the high-density ceilometer networks in the United Kingdom, France and Germany that have been established for monitoring volcanic plumes (Heese et al., 2010). Combined with the ability of lidars to resolve vertical distributions of aerosol properties below cloud layers, collocated and simultaneous measurements of aerosol and cloud are also possible, which can help advance our understanding of aerosol-cloud interactions.

Acknowledgements. This research was supported by the Office of Science (BER), US Department of Energy (DOE), under grant DE-SC0007233. The authors would like to thank Graham Feingold for his stimulating discussion, and Yunyan Zhang for selecting stratiform cases using ARSCL data. We also thank the AERONET team for calibrating and maintaining instrumentation and processing cloud-mode data.

Edited by: Q. Fu

\section{References}

Barnston, A. G.: Correspondence among the correlation, RMSE, and Heidke forecast verification measures; refinement of the Heidke score, Weather Foecast., 7, 699-709, 1992.

Boers, R, and Mitchell, R. M.: Absorption feedback in stratocumulus clouds: Influence on cloud top albedo. Tellus A, 46, 229-241, 1994.

Boers, R. and Rotstayn, L. D.: Possible links between cloud optical depth and effective radius in remote sensing observations, Q. J. Roy. Meteor. Soc., 127, 2367-2383, 2001.

Bony, S. and Dufresne, J: Marine boundary layer clouds at the heart of tropical cloud feedback uncertainties in climate models, Geophys. Res. Lett., 32, L20806, doi:10.1029/2005GL023851, 2005.

Bony, S., Colman, R., Kattsov, V. M., Allan, R. P., Bretherton, C. S., Dufresne, J.-J., Hall, A., Hallegatte, S., Holland, M. M., Ingram, W., Randall, D. A., Soden, B. J., Tselioudis, G., and Webb, M. J.: How well do we understand and evaluate climate change feedback processes?, J. Climate, 19, 3445-3482, 2006.
Bretherton, C. S., Wood, R., George, R. C., Leon, D., Allen, G., and Zheng, X.: Southeast Pacific stratocumulus clouds, precipitation and boundary layer structure sampled along $20^{\circ} \mathrm{S}$ during VOCALS-REx, Atmos. Chem. Phys., 10, 10639-10654, doi:10.5194/acp-10-10639-2010, 2010.

Campbell, J. R., Hlavka, D. L., Welton, E. J., Flynn, C. J., Turner, D. D., Spinhirne, J. D., Scott, V. S., and Hwang , I. H.: Full-time, eye-safe cloud and aerosol lidar observation at Atmospheric Radiation Measurement Program sites: Instruments and data processing, J. Atmos. Ocean. Tech., 19, 431-442, 2002.

Chiu, J. C., Marshak, A., Wiscombe, W. J., Valencia, S. C., and Welton, E. J.: Cloud optical depth retrievals from solar background "signals" of micropulse lidars, IEEE Geosci. Remote S., 4, 456460, 2007.

Chiu, J. C., Huang, C.-H., Marshak, A., Slutsker, I., Giles, D. M., Holben, B. N., Knyazikhin, Y., and Wiscombe, W. J.: Cloud optical depth retrievals from the Aerosol Robotic Network (AERONET) cloud mode observations, J. Geophys. Res., 115, D14202, doi:10.1029/2009JD013121, 2010.

Chiu, J. C., Marshak, A., Huang, C.-H., Várnai, T., Hogan, R. J., Giles, D. M., Holben, B. N., O’Connor, E. J., Knyazikhin, Y., and Wiscombe, W. J.: Cloud droplet size and liquid water path retrievals from zenith radiance measurements: examples from the Atmospheric Radiation Measurement Program and the Aerosol Robotic Network, Atmos. Chem. Phys., 12, 1031310329, doi:10.5194/acp-12-10313-2012, 2012.

Clothiaux, E. E., Ackerman, T. P., Mace, G. G., Moran, K. P., Marchand, R. T., Miller, M. A., and Martner, B. E.: Ojbective determination of cloud heights and radar reflectivities using a combination of active remote sensors at the ARM CART sites, J. Appl. Meteorol., 39, 645-665, 2000.

Del Genio, A. D. and Wolf, A. B.: The Temperature Dependence of the Liquid Water Path of Low Clouds in the Southern Great Plains, J. Climate, 13, 3465-3486, 2000.

Dong, X. and Mace, G. G.: Profiles of low-level stratus cloud microphysics deduced from ground-based measurements, J. Atmos. Ocean. Tech., 20, 42-53, 2003.

Dong, X., Mace, G. G., Minnis, P., Smith, W. L., Poellot, M., Marchand, R. T., and Rapp, A. D.: Comparison of Stratus Cloud Properties Deduced from Surface, GOES, and Aircraft Data during the March 2000 ARM Cloud IOP, J. Atmos. Sci., 59, 3265-3284, doi:10.1175/15200469(2002)059<3265:COSCPD>2.0.CO;2, 2002.

Dong, X., Xi, B., and Minnis, P.: A Climatology of Midlatitude Continental Clouds from the ARM SGP Central Facility. Part II: Cloud Fraction and Surface Radiative Forcing, J. Climate, 19, 1765-1783. doi:10.1175/JCLI3710.1, 2006.

Dupont, J.-C., Haeffelin, M., Morille, Y., Comstock, J. M., Flynn, C., Long, C. N., Sivaraman, C., and Newson, R. K.: Cloud properties derived from two lidars over the ARM SGP site, Geophys. Res. Lett., 38, L08814, doi:10.1029/2010GL046274, 2011.

Ferro, C. A. T. and Stephenson, D. B.: Extremal dependence indices: Improved verification measures for deterministic forecasts of rare binary events, Weather Forecast., 26, 699-713, doi:10.1175/WAF-D-10-05030.1, 2011.

Han, Q., Rossow, W. B., and Lacis, A. A.: Near-global survey of effective droplet radii in liquid water clouds using ISCCP data, J. Climate, 7, 465-497, doi:10.1175/15200442(1994)007<0465:NGSOED>2.0.CO;2, 1994. 
Harshvardhan, Schwartz, S. E., Benkovitz, C. M., and Guo, G.: Aerosol influence on cloud microphysics examined by satellite measurements and chemical transport modeling, J. Atmos. Sci., 59, 714-725, doi:10.1175/15200469(2002)059<0714:AIOCME>2.0.CO;2, 2002.

Hawkins, E. and Sutton, R. T.: The potential to narrow uncertainty in regional climate predictions, B. Am. Meteorol. Soc., 90, 10951107, 2009.

Heese, B., Flentje, H., Althausen, D., Ansmann, A., and Frey, S.: Ceilometer lidar comparison: backscatter coefficient retrieval and signal-to-noise ratio determination, Atmos. Meas. Tech., 3, 1763-1770, doi:10.5194/amt-3-1763-2010, 2010.

Hogan, R. J., Behera, M. D., O'Connor, E. J., and Illingworth, A. J.: Estimating the global distribution of supercooled liquid water clouds using spaceborne lidar, Geophys Res. Lett., 32, L05106, doi:10.1029/2003GL018977, 2004.

Holben, B. N., Eck, T. F., Slutsker, I., Tanre, D., Buis, J. P., Setzer, A., Vermote, E., Reagan, J. A., Kaufman, Y. J., Nakajima, T., Lavenu, F., Jankowiak, I., and Smirnov, A.: AERONET - A federated instrument network and data archive for aerosol characterization, Remote Sens. Environ., 66, 1-16, 1998.

Hogan, R. J., Mittermaier, M. P., and Illingworth, A. J.: The retrieval of ice water content from radar reflectivity factor and temperature and its use in evaluating a mesoscale model, J. Appl. Meteorol., 45, 301-317, 2006.

Illingworth, A. J., Hogan, R. J., O'Connor, E. J., Bouniol, D., Brooks, M. E., Delanoë, J., Donovan, D. P., Eastment, J. D., Gaussiat, N., Goddard, J. W. F., Haeffelin, M., Baltink, K. H., Krasnov, O. A., Pelon, J., Piriou, J.-M., Protat, A., Russchenberg, H. W. J., Seifert, A., Tompkins, A. M., van Zadelhoff, G.-J., Vinit, F., Willen, U., Wilson, D. R., and Wrenchet, C. L.: Cloudnet: Continuous evaluation of cloud profiles in seven operational models using ground-based observations, B. Am. Meteorol. Soc., 88, 883-898, 2007

Kim, B.-G., Schwartz, S. E., Miller, M. A., and Min, Q.: Effective radius of cloud droplets by ground-based remote sensing: Relationship to aerosol, J. Geophys. Res., 108, 4740, doi:10.1029/2003JD003721, 2003.

Kobayashi, T. and Masuda, K.: Effects of precipitation on the relationships between cloud optical thickness and drop size derived from space-borne measurements, Geophys. Res. Lett., 35, L24809, doi:10.1029/2008GL036140, 2008.

Kollias, P., Tselioudis, G., and Albrecht, B. A.: Cloud climatology at the Southern Great Plains and the layer structure, drizzle, and atmospheric modes of continental stratus, J. Geophys. Res., 112, D09116, doi:10.1029/2006JD007307, 2007.

Kubar, T. L., Hartmann, D.-L., Wood. R: Understanding the Importance of Microphysics and Macrophysics for Warm Rain in Marine Low Clouds. Part I: Satellite Observations, J. Atmos. Sci., 66, 2953-2972, doi:10.1175/2009JAS3071.1, 2009.

Lazarus, S. M., Krueger, S. K., and Mace, G. G.: A Cloud Climatology of the Southern Great Plains ARM CART, J. Climate, 13, 1762-1775, doi:10.1175/15200442(2000)013<1762:ACCOTS > 2.0.CO;2, 2000.

Lohmann, U., Tselioudis, G., and Typler, C.: Why is the cloud albedo-particle size relationship different in optically thick and optically thin clouds?, Geophys. Res. Lett., 27, 1099-1102, 2000.
Mann, J. A. L., Chiu, J. C., Hogan, R. J., O’Connor, E. J., L'Ecuyer, T. S., Stein, T. H. M., and Jefferson, A.: Aerosol impacts on drizzle properties in warm clouds from ARM Mobile Facility maritime and continental deployments, J. Geophys. Res.-Atmos., 119, 4136-4148, doi:10.1002/2013JD021339, 2014.

Martin, G., Johnson, D., and Spice, A.: The measurement and parameterization of effective radius of droplets in warm stratocumulus clouds, J. Atmos. Sci., 51, 1823-1842, 1994.

Min, Q.-L. and Harrison, L. C.: Cloud properties derived from surface MFRSR measurements and comparison with GOES results at the ARM SGP site, Geophys. Res. Lett., 23, 1641-1644, 1996a.

Min, Q.-L. and Harrison, L. C.: An adjoint formulation of the radiative transfer method, J. Geophys. Res., 101, 1635-1640, 1996 b.

Min, Q.-L., Duan, M., and Marchand, R.: Validation of surface retrieved cloud optical properties with in situ measurements at the Atmospheric Radiation Measurement Program (ARM) South Great Plains site, J. Geophys. Res., 108, 4547, doi:10.1029/2003JD003385, 2003.

Minnis, P., Heck, P. W., Young, D. F., Fairall, C. W., and Snider, J. B.: Stratocumulus cloud properties derived from simultaneous satellite and island-based instrumentation during FIRE, J. Appl. Meteorol., 31, 317-339, 1992.

Nakagima, T., King, M. D., Spinhirne, J. D., and Radke, L. F.: Determination of the optical thickness and effective particle radius of clouds from reflected solar radiation measurements. Part II: Marine stratocumulus observations, J. Atmos. Sci., 48, 728-751, 1991.

Nakajima, T. Y. and Nakajima, T.: Wide-area determination of cloud microphysical properties from NOAA AVHRR measurements for FIRE and ASTEC regions, J. Atmos. Sci., 52, 4043-4059, 1995.

Naud, C. M., Del Genio, A. D., Haeffelin, M., Morille, Y., Noel, V., Dupont, J. C., Turner, D. D., Lo, C., and Comstock, J.: Thermodynamic phase profiles of optically thin midlatitude clouds and their relation to temperature, J. Geophys. Res., 115, D11202, doi:10.1029/2009JD012889, 2010.

Nauss, T. and Kokhanovsky, A. A.: Discriminating raining from non-raining clouds at mid-latitudes using multispectral satellite data, Atmos. Chem. Phys., 6, 5031-5036, doi:10.5194/acp-65031-2006, 2006.

Painemal, D. and Zuidema, P.: Assessment of MODIS cloud effective radius and optical thickness retrievals over the Southeast $\mathrm{Pa}-$ cific with VOCALS-REx in situ measurements, J. Geophys. Res., 116, D24206, doi:10.1029/2011JD016155, 2011.

Platnick, S.: Vertical photon transport in cloud remote sensing problems, J. Geophys. Res., 105, 22919-22935, 2000.

Sassen, K. and Wang, Z.: Classifying clouds around the globe with the CloudSat radar: 1-year of results, Geophys. Res. Lett., 35 , L04805, doi:10.1029/2007GL032591, 2008.

Sassen, K., Mace, G. G., Wang, Z., Poellot M. R., Sekelsky, S. M., and McIntosh, R. E.: A Case Study Using Coordinated Remote Sensing and Aircraft Measurements. J. Atmos. Sci., 56, 2345-2358, doi:10.1175/15200469(1999)056<2345:CSCACS>2.0.CO;2, 1999.

Schaaf, C. B., Gao, F., Strahler, A. H., Lucht, W., Li, X.W., Tsang, T., Strugnell, N, C., Zhang, X. Y., Jin, Y. F., Muller, J. P., Lewis, P., Barnsley, M., Hobson, P., Disney, M., Rober ts, G., Dunderdale, M., Doll, C., d'Entremont, R. P., Hu, B. X., Liang, S. 
L., Privette, J. L., and Roy, D.: First operational BRDF, albedo nadir reflectance products from MODIS, Remote Sens. Environ., 83, 135-148, 2002.

Sengupta, M., Clothiaux, E. E., and Ackerman, T. P.: Climatology of warm boundary layer clouds at the ARM SGP site and their comparison to models, J Climate, 17, 4760-4782, doi:10.1175/JCLI3231.1, 2004.

Stamnes, K., Tsay, S.-C., Wiscombe, W. J., and Jayaweera, K.: Numerically stable algorithm for discrete-ordinate-method radiative transfer in multiple scattering and emitting layered media, Appl. Optics, 27, 2502-2512, 1988.

Stephens, G. L.: Radiation profiles in extended water clouds I: Theory, J. Atmos. Sci., 35, 2111-2122, doi:10.1175/15200469(1978)035<2111:RPIEWC>2.0.CO;2, 1978.

Stokes, G. M. and Schwartz, S. E.: The Atmospheric Radiation Measurement (ARM) Program: Programmatic background and design of the cloud and radiation test bed, B. Am. Meteorol. Soc., 75, 1201-1221, 1994.

Suzuki, K., Nakajima, T., Nakajima, T. Y., and Khain, A. P.: A study of microphysical mechanisms for correlation patterns between droplet radius and optical thickness of warm clouds with a spectral bin microphysics cloud model, J. Atmos. Sci., 67, 11261141, doi:10.1175/2009JAS3283.1, 2010.

Suzuki, K., Stephens, G. L., van den Heever, S. C., and Nakajima, T. Y.: Diagnosis of the warm rain process in cloud-resolving models using joint CloudSat and MODIS observations, J. Atmos. Sci., 68, 2655-2670, doi:10.1175/JAS-D-10-05026.1, 2011.
Szczodrak, M., Austin, P. H., and Krummel, P. B.: Variability of optical depth and effective radius in marine stratocumulus clouds, J. Atmos. Sci., 58, 2912-2926, doi:10.1175/15200469(2001)058<2912:VOODAE>2.0.CO;2, 2001.

Turner, D. D., Clough, S. A., Liljegren, J. C., Clothiaux, E. E., Cady-Pereira, K., and Gaustad, K. L.: Retrieving liquid water path and precipitable water vapor from Atmospheric Radiation Measurement (ARM) microwave radiometers, IEEE T. Geosci. Remote, 45, 3680-3690, doi:10.1109/TGRS.2007.903703, 2007.

Welton, E. J. and Campbell, J. R.: Micropulse lidar signals: Uncertainty analysis, J. Atmos. Ocean. Tech., 19, 2089-2094, 2002.

Wood, R.: Stratocumulus clouds, Mon. Weather Rev., 140, 2373 2423, doi:10.1175/MWR-D-11-00121.1, 2012.

Wood, R. and Harmann, D. L.: Spatial Variability of Liquid Water Path in Marine Low Cloud: The Importance of Mesoscale Cellular Convection, J. Climate, 19, 1748-1764, 2006.

Xi, B., Dong, X., Minnis, P., and Khaiyer, M. M.: A 10 year climatology of cloud fraction and vertical distribution derived from both surface and GOES observations over the DOE ARM SPG site, J. Geophys. Res., 115, D12124, doi:10.1029/2009JD012800, 2010.

Yang, Y., Marshak, A., Chiu, J. C., Wiscombe, W. J., Palm, S. P., Davis, A. B., Spangenberg, D. A., Nguyen, L., Spinhirne, J. D., and Minnis, P.: Retrievals of thick cloud optical depth from the Geoscience Laser Altimeter System (GLAS) by calibration of solar background signal, J. Atmos. Sci., 65, 3513-3526, doi:10.1175/2008JAS2744.1, 2008. 